\title{
O DIABO COMO PERSONAGEM NA LITERATURA INFANTIL
}

Poliana Bernabé Leonardeli ${ }^{1}$

Resumo: A partir do século XVII, inúmeros autores, como os irmãos Grimm e Hans Christian Andersen, pesquisaram e, posteriormente, publicaram histórias baseadas no folclore popular europeu. Como o período em que tais fenômenos ocorreram converge com o nascimento da família burguesa, que redirecionou a visão acerca da criança, as histórias produzidas por esses autores acabaram por ser elaboradas e adaptadas ao universo infantil. A figura do diabo fazia parte da memória coletiva europeia, sua presença é notadamente perceptível no ideário da Idade Média, logo, a inserção desse personagem em obras fictícias para crianças tornou-se comum nos enredos infantis da época. $O$ artigo analisará, em alguns contos produzidos entre os séculos XVIII e XIX, as similitudes perceptíveis na criação do personagem, e comprovará seu caráter folclórico, bem como sua construção literária a partir de um denominador coletivo comum: a memória popular.

Palavras-chave: Diabo. Memória Coletiva. Literatura Infantojuvenil.

\section{O espaço da memória coletiva na formação de uma literatura infantojuvenil}

Os primeiros livros endereçados às crianças surgiram no século XVII, por isso, a muitos convém determinar esse período como o marco de surgimento de uma literatura endereçada a um novo público: o infantojuvenil. O conceito de infância se reelaborava na época. Segundo Ariès (1978, p.42) "na Idade Média considerava-se a infância como um período caracterizado pela inexperiência, dependência e incapacidade de corresponder a demandas sociais mais complexas". Nessa época, a criança era vista como um adulto em miniatura e, por isso, trabalhava nos mesmos locais, usava as mesmas roupas e já era tratada como adulto. No século XVII, surge uma preocupação com a formação moral da criança e com a sua construção como indivíduo social.

Ainda segundo Ariès (1978, p.45), "a partir do século XVIII, as crianças começaram a ser reconhecidas em suas particularidades". A concepção de infância nascia devido a mudanças ideológicas advindas da classe burguesa, daí surge também a necessidade de adaptação de uma literatura a esse público. Como os textos elaborados buscavam defender o discurso da burguesia, eram, em sua grande maioria, moralistas e de caráter maniqueístas. Porém, os textos infantis escritos naquela época também, muitos deles, baseavam-se em pesquisas

\footnotetext{
${ }^{1}$ Mestre em Estudos Literários pela Universidade Federal do Espírito Santo, UFES, Brasil, docente efetivo na Secretaria Estadual de Educação (SEDU).
}

Revista de Letras JUÇARA, Caxias - Maranhão, v. 03, n. 01, p. 160 - 174, ago. 2019 | 160 
folclóricas, os primeiros escritores infantis, como os irmãos Grimm, não criavam, mas tão somente reelaboravam histórias de cunho popular ouvidas de contadores, dando-Ihes um verniz próprio, mas mantendo no enredo de seus escritos um caráter literário e folclórico, que expressava a cultura regional da época, não se desvinculando das profundas raízes do passado, das memórias coletivas do povo, suas tradições e aspirações.

Os contos de fada, conhecidos atualmente, foram, em sua maioria, editados a partir de narrativas folclóricas contadas por pessoas pertencentes a camadas populares, retirando-se passagens consideradas impróprias para a época. Mas, muito antes mesmo da existência de livros infantojuvenis, já se contavam histórias às crianças e adultos. Meireles (2016, p. 35) destaca que "nos primórdios da humanidade, a literatura já era utilizada, feita de modo informal”, ou seja, não era nomeada como literatura, porém já se manifestava nas transmissões de valores dos povos antigos, por meio de histórias contadas por antepassados. Não existiam ainda livros infantis, porém, as falas dos mais velhos, fossem elas lendas, contos de fadas, folclore, ou até mesmo aquelas criadas da imaginação, eram a representação dos livros que hoje chamamos de literatura infantil.

Da vasta produção de histórias populares, a priori oral e de caráter folclórico e depois escrita e institucionalizada, é possível explorar uma gama imensa de personagens fictícios que compuseram e continuam a compor o imaginário coletivo da humanidade diversificando-se em inúmeros gêneros literários e/ou audiovisuais.

Foi na Europa, propriamente, que se deu a compilação dessas narrativas de tradição oral que circulavam entre os povos da Idade Média e também sua adaptação ao público infantil. Os primeiros livros infantis apresentavam narrativas curtas, daí denominarem-se contos. Esses textos adaptavam a ideologia burguesa a histórias e narrações tradicionais, que existiam desde os tempos mais antigos, sendo essas histórias orais em sociedade ágrafas e transmitidas de geração em geração por meio da oralidade (ZUMTHOR 1993, p.80).

A preocupação dos primeiros folcloristas que copilaram todo o material a fim de preservá-lo do esquecimento, já que "a escrita tornava-se preponderante no período em relação à oralidade" (ZUMTHOR, 1993, p.76), foi certamente preservar a memória coletiva. Foi o sociologista francês Maurice Halbwachs que cunhou o termo a fim de conceituar o fenômeno que surge da interação social, o sociólogo 
observou como as representações coletivas do mundo, incluindo as do passado, tinham suas origens na interação de entidades coletivas desde o início e que não poderiam ser reduzidas a contribuições de indivíduos pois "eventos e experiências lembrados são raramente constituídos por indivíduos à parte de outros ou de seu grupo social" ( HALBWACHS, 2006, p.28).

Para pensar em tais constituições coletivas da memória humana, podemos nos apoiar também nas teorias de Bakhtin, segundo as quais os seres humanos são animais que utilizam signos e desenvolvem formas de ação especiais, como falar e pensar, envolvendo uma "combinação não redutível de um agente ativo e uma ferramenta cultural" (BAKHTIN, 2003 p. 223). Isso significa que a evolução do pensamento social não é um processo individual, mas fruto do meio no qual está inserido o indivíduo.

A partir dos estudos de Bakhtin, pode-se destacar que o texto é importante instrumento de mediação para conservação da memória coletiva. Essa noção de texto é desenvolvida por Bakhtin a partir de duas perspectivas. Segundo ele:

\begin{abstract}
Cada texto pressupõe um sistema de signos geralmente compreendido (isto é, convencional dentro de um determinado coletivo), uma linguagem compreendida de modo geral (...). E então por trás de cada texto, há um sistema de linguagem. Tudo no texto que é repetido ou reproduzido, tudo que é repetível ou reproduzível, tudo que pode ser dado fora de um determinado texto (o dado) está em conformidade com esse sistema de linguagem. No entanto, ao mesmo tempo, cada texto (como uma enunciação) é individual, único e não repetível, e aqui reside sua inteira significação (seu plano, o propósito, para o qual ele foi criado) (BAKHTIN, 2003, p. 245)
\end{abstract}

Pensar a memória coletiva sob a perspectiva bakhtiniana é propício a esta discussão por considerar, em especial, a noção de enunciação em uma dimensão dialógica da atividade discursiva, vista como forma própria e significativa de linguagem humana. Essa concepção de linguagem toma a língua como um processo de enunciação sócio histórica, cuja produção de sentidos se dá em situações de interlocução, procurando estabelecer relações entre o discurso e as condições sociais e históricas de produção.

Tal concepção de linguagem ancora-se em efeitos de sentido que não são únicos, universais, atemporais e convencionais, mas que são expressos entre interlocutores inseridos nas instituições sociais que atuam sobre eles. Segundo

Revista de Letras JUÇARA, Caxias - Maranhão, v. 03, n. 01, p. 160 - 174, ago. 2019| 162 
essa concepção, a construção dos sentidos se dá via interação; os sentidos não são dados a priori, são construídos durante o ato discursivo, como os contos populares infantis e/ou outras narrativas orais diversificadas, que ainda hoje povoam a memória coletiva e carregam consigo a memória popular e a consciência de inúmeros contextos, por isso acabam por tornar-se um fecundo território de pesquisa acerca da formação dos discursos a partir de uma consciência coletiva, daí um número considerável de pesquisas sobre narrativas orais ter sido desenvolvido nos últimos anos.

Vislumbrando na sociedade burguesa que se apresentava, um predomínio da escrita sobre a oralidade e a perda de todo esse aparato cultural e a fim de preservar toda uma série de contos populares de origens indeterminadas em uma sociedade que segundo Zumthor (1993, p.80) "se individualizava e que abandonava os hábitos da coletividade, da oratória e das festividades populares", os folcloristas, assim eram denominados esses autores, pesquisaram e, posteriormente, publicaram uma série de contos adaptados à infância e juventude. Essas histórias buscavam unir o moralismo, próprio do conservadorismo burguês que ora se instalava, às histórias populares narradas por pessoas comuns do povo, na ansiedade de preservá-las do esquecimento.

O anseio por atender às demandas dessa nova sociedade, mais a tentativa de se ater ao nacionalismo, outra tendência da época, acabou por dar origem a um gênero literário inovador: os contos infantis. $O$ fato de que essas histórias continuam a ser lidas, readaptadas e ainda atendem a todo um público em pleno século tecnológico, serve para nos mostrar como a memória, por meio da palavra escrita, ainda une o homem a uma consciência coletiva e ancestral.

A este artigo caberá explorar como se dá a construção da figura do diabo nas primeiras produções infantis europeias, observando nessa construção a relação com a memória popular coletiva e com a moral burguesa nascente. Para tanto foram escolhidos para análise três contos publicados entre os séculos XVII e XVIII: Pele de Urso dos irmãos Grimm, O moinho do diabo de Hans C. Andersen e Carvões para a lareira do diabo (conto irlandês de autoria desconhecida).

\section{A imagem do diabo na literatura infantojuvenil: uma construção da cultura popular e dos valores burgueses nascentes}

Revista de Letras JUÇARA, Caxias - Maranhão, v. 03, n. 01, p. 160 - 174, ago. 2019| 163 
Inúmeros são os autores que utilizam a figura do diabo em sua produção literária, sejam eruditos ou populares. O personagem é abordado em todas as épocas e contextos históricos, tanto em situações de questionamentos existenciais como em Guimarães e Dostoievski, ou em situações cômicas, vistas na obra vicentina, por exemplo. Em todas as épocas, estilos e gêneros, é possível encontrar a figura do diabo interagindo com a consciência humana. Com a literatura infantojuvenil não é diferente. Porém, dadas as peculiaridades dos primeiros textos infantis, é possível observar uma abordagem um tanto quanto folclórica e popular dessa figura nos textos em que ela é retratada, essa construção da imagem do diabo nos primeiros contos infantis está ancorada em uma memória popular coletiva, mas não deixa de atender a um outro anseio do período, a moralização advinda dos valores burgueses.

A construção da figura do diabo deu-se em tempos remotos, muito antes da elaboração dos primeiros livros infantojuvenis, ainda na Idade Antiga, "em civilizações não judaicas já é possível perceber figuras que representavam a consciência da dualidade" (FERRAZ, 2007, p.85). Na sociedade medieval, o diabo aparece como um grande protagonista, fruto de uma visão teocêntrica do mundo, baseada em dicotomias e de caráter maniqueísta (NOGUEIRA, 1986, p.45). Independentemente da origem ou peculiaridades dessa figura, o fato é que a cultura Ocidental não fica indiferente a essa crença. Identificado pelo nome de diabo, mas também por outros codinomes, sua figura está presente em todos os âmbitos e esferas sociais. Para Carlos Roberto Nogueira (1986), no texto O Diabo no Imaginário Cristão, tamanha repercussão deve-se especialmente à difusão de um dos dogmas centrais do cristianismo: bem $x$ mal. Segundo Nogueira (1986, p. 103) "com o advento do Cristianismo, chocam-se as tradições, interpenetrando-se e amoldando-se, esse confronto antagônico permanente é vital para a construção da figura maligna na consciência cristã".

A Bíblia também influenciou o pensamento Ocidental e, por isso, suas artes, incluindo nestas a literatura. Em seu artigo $A$ esfinge pejada de mistérios: travessias e travessuras de Judas, Salma Ferraz enfatiza que sendo a Bíblia (...) "o maior best-seller de todos os tempos é natural que muitos de seus personagens migrem para as páginas de grandes romances do Ocidente" (FERRAZ, 2007, p.2). Entretanto, nos textos populares, o diabo é apresentado como uma figura menos 
maligna do que nos textos cristãos, assumindo ares cômicos ou ingênuos de acordo com o gênero textual em que é retratado, o que pode ser visto como uma reação da cultura popular e da consciência coletiva ao uso dessa figura como forma de manipulação social, retirando-lhe as características amedrontadoras e reconstruindo-a de modo mais ameno.

Nesse contexto, é verificável que o diabo assume um papel de maior fragilidade do que lhe é atribuído pelo cristianismo e uma visão muito diferente da cristã no que concerne a sua relação com os seres humanos, distanciando-se da figura construída pela igreja. A busca do artigo é retratar algumas das características que envolvem a figura do diabo nas narrativas populares infantis, comprovando seu caráter folclórico e sua visão popularesca como veremos a seguir.

São muito comuns nas histórias populares que envolvem a figura do diabo, a presença de um pacto entre essa figura e um personagem humano. A tradição oral e, posteriormente, a literatura escrita possuem vários protagonistas que firmaram o acordo com o tinhoso. Em geral, são enredos nos quais o diabo apresenta-se a um homem ou uma mulher e propõe algo: realizar os desejos daquele mortal por determinado período e, como pagamento, possuir a alma deste pela eternidade. Muito se escreveu sobre os pactos que um diabo sedutor estabelece com os homens.

Nas histórias populares infantis, segundo Luís Câmara Cascudo (2009), apresenta-se grande diversidade de narrativas sobre pactos entre humanos e entes mágicos, das quais tomou maior repercussão os folhetos populares com o final frustrante para o Diabo, quando ele, "ao invés de exercer o ápice de seu poder, condenando uma alma ao inferno, é enganado pelo homem ou mulher com quem realiza o acordo" (CASCUDO, 2009, p.67).

Outra característica dos contos infantis que abordam o tema é a esperteza da mulher em detrimento do discurso do diabo. Segundo Salma Ferraz, no seu artigo $O$ diabo na literatura para crianças, "as filhas de Eva têm facilidade em lidar com o Diabo e os homens se mostram muito mais ingênuos" (2007, p. 4). Em outras histórias como nos cordéis nordestinos o diabo pode ser enganado por um personagem masculino que, apesar de suas condições de miséria, apresenta-se 
muito esperto, é o que analisa Luís Câmara Cascudo naquilo que chama de Ciclo do diabo logrado:

(...) definindo as narrativas que compõem esse ciclo como aquelas histórias em que um indivíduo faz um pacto qualquer com o Diabo, oferecendo sua alma em troca de um benefício qualquer, e depois o Diabo aparece para cobrar o prometido (Cascudo). O sujeito (geralmente com a ajuda da esposa) acaba inventando um estratagema para se ver livre do Tinhoso. É um tema comum a todos os folclores, de todas as épocas (2009, p.79).

Outra característica própria desses contos é a presença do aspecto moralizador, o uso do moralismo prestava-se a uma função educadora, dado que a criança, agora assim vista, estava em um período de formação de consciência o moralismo buscava atender aos anseios da burguesia, uma classe que baseava seus comportamentos em visões conservadoras. Para Moure (2013, p.6), havia muita intenção moralizante na literatura infantil daquele período, acompanhada de uma função pedagógica. Havia uma preocupação em formar as crianças.

Na vida cotidiana, poucas vezes somos capazes de nos dirigir às crianças de forma horizontal sem tentar ensinar. A literatura infantil não é infantil nunca e a juvenil poucas vezes é juvenil. São os adultos, possuidores de valores humanos e humanísticos firmes, que escrevem para eles e este "para" é o pecado original da literatura infanto-juvenil (Moure, 2013, p.4)

De acordo com o escritor, essa prática ainda se reflete em obras literárias do gênero, com livros destinados à prevenção e que não abordam assuntos considerados tabus, como sexo e religião. "O editor, disfarçadamente ou conscientemente, publica tais livros. E o escritor se submete a essa exigência" (MOURE, 2013, p.4). Foi esse aprisionamento que fez com que "a literatura infantojuvenil fosse vista ou classificada como um subgênero literário" (2013, p.4), explica o autor. Em sua avaliação, o mundo é ainda muito polarizado, entre o bem versus o mal. "Se ela não se desprender do maniqueísmo imperante, será sempre um subgênero" (MOURE, 2013, p.3).

Em busca de exemplificar essas características acima apresentadas, serão feitas as análises de três contos do período: Pele de Urso dos irmãos Grimm, $O$ moinho do diabo de Hans C. Andersen e Carvões para a lareira do diabo (conto 
popular irlandês). Por meio da análise buscar-se-á comprovar o caráter folclórico do personagem, dado que nas três narrativas, a estrutura do enredo e a situação como o diabo se configura são muito semelhantes, bem como a presença do aspecto moralizador, presente em cada um deles, próprio da camada burguesa.

\section{Pele de Urso}

Em Pele de Urso, conto dos irmãos Grimm, a personagem protagonista após ser rejeitada pela família ao voltar da guerra, onde fora soldado, e não ter mais seu lugar no mundo, como lhe diz um dos irmãos: "Que faremos contigo? Não entendes nada dos trabalhos do campo e não há lugar para ti; arranja-te como puderes"( Grimm apud Magalhães, 1973, p. 143), é interpelada pelo diabo, que possui uma boa figura, apesar de ter um casco de cavalo: "viu a dois passos um desconhecido trajando um casaco verde, com ares de fidalgo, mas um de seus pés era um monstruoso casco de cavalo", é convidado a um acordo, no caso a um pacto, cujo preço seria a perda da alma, caso derrotado durante o desafio, ou uma recompensa em dinheiro, que no linguajar do diabo seria a vontade, caso vencesse as dificuldades. Entretanto, o desafio seria grande, pois consistia no seguinte sacrifício, segundo o tinhoso:

(...) durante os próximos sete anos, não te lavarás, nem te pentearás, não deves cortar os cabelos, as unhas nem a barba e, tampouco, deves dizer um único Padre-Nosso. Se morreres nesse intervalo, a tua alma será minha; se não morreres, então serás livre e rico pelo resto da tua vida (Grimm apud Magalhães, 1973, p.143)

A personagem não é obrigada a aceitar o que o diabo lhe oferece, mas a dificuldade momentânea que atravessa, o imediatismo, bem como a boa lábia do diabo acabam por sobreporem-se às dificuldades vindouras.

É interessante perceber que o soldado se apresenta em uma situação de completo abandono, em todas as outras histórias em que ocorre a sugestão do pacto, o diabo sempre escolhe suas vítimas em situações frágeis, essas personagens pertencem também às camadas mais frágeis da sociedade, e elas não vislumbram uma saída possível para a situação em que se encontram. 
A aceitação do acordo conduz o jovem a seu desafio, que deverá ser vencido pela personagem em um tempo determinado. $O$ jovem soldado do conto deveria "usar durante sete anos uma pele de urso, não podendo retirá-la, banharse ou mesmo dormir sem aquela pele a cobrir-Ihe" (Grimm apud Magalhães, 1973, p.144). O número sete aparece inúmeras vezes na bíblia, é considerado o número perfeito, uma vez que parece representar o início e o fechamento de um ciclo (Grimm apud Magalhães, 1973, p.144). Na narrativa é empregado em sentido semelhante. Após um ano com a vestimenta, o jovem já não era mais reconhecido como humano, uma vez que suas feições foram transformadas. $O$ desafio parece grande demais levando o personagem ao desânimo e questionamento acerca de sua escolha.

Porém, em Pele de Urso, a mudança no plano de vida da personagem dáse muito no ponto de vista físico, já que o protagonista tem seu aspecto exterior alterado e, inclusive, recebe uma alcunha, perdendo sua identidade. Mas essa mudança não ocorre no plano psicológico, em nenhuma circunstância percebe-se que a personagem tenha se animalizado em função do aspecto monstruoso que adquirira ao longo dos meses. Inclusive, é por manter sua bondade que consegue vencer a artimanha do diabo.

Bondoso, como sempre fora, ele ajuda um ancião em dificuldade e, além da guarida por uma noite, o senhor oferece-lhe uma de suas filhas. Temerosas quanto à imagem de Pele de Urso, todas as meninas se esquivam do ser de aspecto monstruoso, menos a mais nova e bonita delas, que promete esperá-lo pelos próximos anos, sem saber ao certo o porquê disso, nem se Pele de Urso retornaria. A moça explica ao pai a razão de sua estranha aceitação: "Meu pai, ele deve ser um homem muito bom, desde que te socorreu na tua aflição; se em troca da sua generosidade the prometeste uma das tuas filhas, tens de manter a palavra dada" (Grimm apud Magalhães, 1973, p.144). Seguindo um aspecto moralizador presente nessas histórias, a moça não julga pela imagem e acata os anseios do progenitor, aceitando submissa as ordens paternas.

A moralidade em Pele de Urso insere-se também no universo comportamental do protagonista. Por manter sua personalidade bondosa, a personagem vence o desafio proposto e é recompensada pelo tesouro infinito e 
pelo amor verdadeiro. Já que ao abandonar a pele, banha-se, perfuma-se e retorna, como havia prometido, à casa do ancião para casar-se com uma de suas filhas:

\footnotetext{
Minha querida, - disse ele, - eu sou o noivo e tu o conheceste como o Pele de Urso; mas, por graça de Deus, recuperei a figura humana e estou inteiramente limpo daquela imundície que me recobria todo. Agora voltei para te desposar. Aproximou-se-Ihe com grande ternura, estreitou-a nos braços e beijou-a (Grimm apud Magalhães, 1973, p.145)
}

As irmãs más e invejosas da noiva, por terem-no julgado pela aparência e não aceitarem a imposição paterna, acabam morrendo de forma trágica: ambas cometem suicídio, a mais velha joga-se em um poço e a mais nova enforca-se em uma figueira. De acordo com a teologia cristã, o suicida tem a alma entregue ao diabo. Ao final, e de forma sarcástica, o tinhoso afirma não ter sido de todo derrotado, já que conseguiu as almas humanas que tanto almejava: "- Não fiz tão mau negócio. Perdi a tua alma mas, em compensação, ganhei duas" (Grimm apud Magalhães, 1973, p.145).

\section{O Moinho do diabo}

Em O moinho do diabo, conto de H. C. Andersen, é apresentada a figura do moleiro, também ele pertencente à classe menos privilegiada. Em apuros financeiros devido às condições de seu moinho, construído em local impróprio, já que os ventos não alcançavam suas pás, encontrava-se cercado de uma prole esfomeada e cheia de necessidades, sob tal dificuldade é interpelado pelo diabo, que the oferece um acordo: a construção e entrega em uma noite de um majestoso moinho que the daria 12 anos de grande prosperidade, nota-se aqui outro número que é muito citado na Bíblia e representa também um ciclo, com início e fechamento, o número 12, assim como o número 7 , presente na narrativa explorada anteriormente, carregam forte aspecto simbólico. Segundo Nogueira (1986), há referência de seu uso a partir de aspectos místicos em diversas civilizações antigas, ficando mais conhecidos dos contemporâneos devido sua presença no livro sagrado do cristianismo.

Ao fim desse período, a alma do moleiro seria entregue ao diabo. Por verse em grande dificuldade ou por não acreditar na possibilidade da construção do

Revista de Letras JUÇARA, Caxias - Maranhão, v. 03, n. 01, p. 160 - 174, ago. 2019|169 
moinho em uma noite, ou seja, duvidando das artimanhas do diabo, o moleiro não declina da proposta. Porém, para sua decepção, a construção dá-se por feitiço e antes que o dia nascesse o moinho já estaria pronto. Ao perceber tal situação, a personagem intervém na execução do projeto

\begin{abstract}
Pressentindo a aurora, correu então para a mó e, com a força do desespero, arrancou a cunha que a sustinha. E o pesado bloco de pedra rolou fragorosamente pelas encostas do monte. O construtor de moinhos e seus infernais ajudantes soltaram um grito uníssono e terrível, correndo vertiginosamente atrás da pedra, ao mesmo tempo em que o moleiro, por sua vez, também, corria, na direção oposta, pelo monte abaixo. Já o diabo agarrara a mó e se aprestava a subir, com ela, para colocá-la no moinho, quando os galos começaram a cantar (Andersen apud Magalhães, 1973, p. 179)
\end{abstract}

Interessante perceber nessa narrativa que há o desafio pessoal do diabo para consigo mesmo, uma vez que ele teria de construir um grande moinho em um curtíssimo espaço de tempo. No período em que o moleiro se aproveitaria do moinho, ele também receberia "uma bolsa cujo interior sempre teria moedas a tilintar" (Andersen apud Magalhães, 1973, p. 179). A mudança de vida não ocorre com o moleiro, nem do ponto de vista físico ou psicológico, ao intervir no trabalho dos serviçais do diabo que construíam a torre, perde as riquezas posteriores, mas também evita a perda da alma.

Furioso por não ter podido consumar os seus planos, apoderando-se de mais uma alma, o maldito atirou a mó contra o moinho, que se desfez em pedaços, espalhados ao redor, até muito longe. Quem hoje sobe ao monte Ramberg lá encontra apenas uma escura massa de granito, a que o povo ainda dá o nome de Moinho do Diabo. (Andersen apud Magalhães, 1973, p. 181).

O moralismo consiste em um premente arrependimento e em um desfecho que (a grosso modo) significa que mais vale o sofrimento terreno do que os prazeres a qualquer custo em troca de uma eternidade no inferno, o que é certamente uma visão de caráter teocêntrica e medieval, livre do pacto que firmara num momento de fraqueza, o moleiro voltou para junto da família, disposto a sofrer resignadamente as provações que Ihe reservava o destino: "Mais valia ser pobre que vender-se ao diabo por todas as riquezas do mundo". (Andersen apud Magalhães, 1973, p.181).

Revista de Letras JUÇARA, Caxias - Maranhão, v. 03, n. 01, p. 160 - 174, ago. 2019 | 170 


\section{Carvões para a lareira do diabo}

No conto Carvões para a lareira do diabo, de origem irlandesa e de autoria desconhecida, novamente nos deparamos com o protagonista em desespero, sem condições mínimas de sustento, como se percebe no trecho: "Era uma vez um homem muito, muito pobre. Ele tinha mulher e oito filhos para criar, trabalhava de sol a sol e ganhava uma miséria" (Machado, 2004, p.48), desesperado o personagem sai em peregrinação numa noite, quando se depara com a figura diabólica. Ao contrário dos outros contos, neste o tinhoso é apresentado na forma clássica: peludo, fedorento e com partes animalescas na estrutura física. A semelhança das outras narrativas são oferecidas ao homem riquezas e benesses, caso vendesse a alma ao tinhoso. A recompensa consistia no recebimento de um tambor e sempre que o tocasse, o diabo apareceria e faria o que o protagonista desejasse, isso durante um tempo determinado. Nota-se, também, a simpatia e o charme do diabo durante a conversa.

\footnotetext{
O outro foi chegando, com a fala aveludada, foi convidando para tomar um trago, dizendo que a vida não era assim tão complicada, que tinha jeito pra tudo neste mundo Depois, sem muitos rodeios, foi logo propondo: É muito simples, eu posso resolver seus problemas de uma vez por todas. É claro, com uma condição. Se você concordar em me vender sua alma, sua vida vai ficar uma maravilha (Machado, 2004, p. 49).
}

A personagem, em desespero, como os outros aqui descritos, aceita. Porém, nessa história há a presença da figura da mulher que intervém na situação agindo de forma um tanto quanto esperta. Nos contos populares do período, a mulher, quando em situações de confronto com o diabo, apresenta-se com mais esperteza que a figura diabólica. Segundo Ferraz (2009, p.88): "As filhas de Eva têm facilidade em lidar com o Diabo e os homens se mostram muito mais ingênuos". Ao saber do acordo e a fim de fazer com que o pacto funcionasse de modo que resolvesse os problemas financeiros da família e não terminasse de forma catastrófica para o marido, ela sugere:

Bom - disse a mulher - nem tudo está perdido. Você não disse que tinha uma história de um tambor, que é só você tocar que o diabo aparece e faz o que você pedir? Pois eu tenho um plano para a gente ficar livre dele. Toque o tambor e, quando ele vier, diga para ele construir igrejas e

Revista de Letras JUÇARA, Caxias - Maranhão, v. 03, n. 01, p. 160 - 174, ago. 2019 | 171 
capelas, muitas, por toda parte. - Que boa idéia, mulher - disse o homem muito animado. - Imagine se demônio que se preza vai se meter em negócio de igreja. (MACHADO, 2004, p. 50).

O diabo atende ao pedido inusitado da mulher sugerindo que ele construísse templos cristãos, o que é prontamente atendido. Surpresa, a mulher afirma: "um diabo obreiro do Cristianismo", mas não se dando por vencida, pensa em outro pedido, com que objetivava enganar o diabo. Confiando na mulher, o marido pede o seguinte ao diabo:

- Pois o meu pedido é uma coisinha à-toa, não vai custar nada para você. Eu quero que você transforme todo o pessoal que manda aqui neste mundo: rei, presidente, deputado, senador, juiz, delegado, você sabe, toda essa gente. Quero que você faça eles virarem pessoas honestas. (MACHADO, 2004, p. 51).

Ao atender ao pedido, todo o mal sobre o mundo acaba e a lareira que alimentava o diabo não mais se acende. A lógica final do conto se dá ao se constatar que sem as maldades e desmandos dos poderosos nem um mal acende a fogueira do diabo e este deixa de existir. Nessa visão, a maldade humana alimenta o diabo e não o contrário. Uma visão mais popularesca do diabo, já perceptível no final da Idade Média nos teatros vicentinos, por exemplo. Sendo, de acordo com tal pensamento, o homem artífice da própria existência.

\section{Considerações finais}

A literatura infantojuvenil entre os séculos XVII e XIX, de acordo com o que é apresentado no artigo e referenciado por pesquisadores, tornou-se um espaço de preservação de uma memória coletiva popular. Atendendo aos anseios moralizantes da burguesia, mas também explorando o folclore popular a fim de preservá-lo em um forte anseio nacionalista, diversos autores criaram um gênero inusitado que, se por um lado encontra-se empobrecido por estar a serviço dos anseios de uma classe econômica, a burguesia e sua ideologia conservadora, por outro explora a cultura popular, "hostil a toda perfeição definitiva, a toda estabilidade, a toda formalidade limitada, a toda operação e decisão circunscritas ao domínio do pensamento e à concepção do mundo." (BAKHTIN, 2003, p.267) 
sucesso rápido dessa literatura e o sentido que ainda faz na sociedade contemporânea dá-se muito mais pela presença dessa memória coletiva do que pelos ares moralizantes que lhe foi imposto pela circunstância histórica. A figura do diabo e a exploração dela em alguns contos infantojuvenis demonstraram que esse espaço literário foi o palco de discurso de uma classe econômica que crescia e ocupava todos os espaços da sociedade contemporânea, mas que a força dessa literatura e sua sobrevivência estão muito mais atreladas à cultura popular e a memória coletiva dos povos do que a um projeto ideológico de poder.

A partir de tal lógica, percebe-se que não é simplesmente o apelo pedagógico da literatura infantojuvenil em seus anos nascentes, mas a profunda originalidade da antiga cultura popular, presente nessa literatura, a responsável no enredo por todo o enfrentamento e autenticidade que sustenta o gênero, um sucesso entre adultos e crianças de todos os tempos.

\title{
THE DEVIL AS CHARACTER IN THE INFANTIL LITERATURE
}

\begin{abstract}
In the 17th century, numerous authors, such as the brothers Grimm and Hans Christian Andersen, researched and later published stories based on popular European folklore. As the period in which such phenomena occurred converged with the birth of the bourgeois family, which redirected the vision about the child, the stories produced by these authors were elaborated and adapted to the infant universe. The figure of the devil was part of the European collective identify, its presence is noticeably noticeable in the Middle Ages, so the insertion of this character into fictional works for children became common in the children's plots of the time. The article will analyze, in some tales produced between the eighteenth and nineteenth centuries, the perceptible similarities in the construction of the character, and will prove its folkloric character, as well as its literary construction from a common denominator common: the popular memory.
\end{abstract}

Keywords: Devil. Collective Memory. Children's Literature.

\section{Referências}

ARIÈS, P. História social da infância e da família. Tradução: D. Flaksman. Rio de Janeiro: LCT, 1978

BAKHTIN, Mikhail. A cultura popular na idade média e no renascimento: o contexto de François Rabelais. (Trad. de Yara Frateschi Vieira). 3. ed. São Paulo/Brasília: Editora Universidade de Brasília, 1993.

2003.

. Estética da Criação Verbal. São Paulo: Martins Fontes,

Revista de Letras JUÇARA, Caxias - Maranhão, v. 03, n. 01, p. 160 - 174, ago. 2019 | 173 
BíBLIA SAGRADA. Tradução de João Ferreira de Almeida. Edição revista e corrigida. Rio de Janeiro: Sociedade Bíblica do Brasil, [s.d].

CASCUDO, Luis da Câmara. Contos Tradicionais do Brasil. São Paulo: Global, 2009.

DELUMEAU, Jean. História do Medo no Ocidente: 1300-1800 uma cidade sitiada. Tradução de Maria Lucia Machado. Tradução das notas Heloisa Jahn. São Paulo: Companhia das Letras, 1989. $5^{\text {a }}$ reimpressão. 978.

FERRAZ, Salma. O diabo na literatura para crianças. Vertentes (UFSJ. V.43, p. 8397,2009 .

A esfinge pejada de mistérios: travessias e travessuras de Judas, 2007. Disponível em:http://www.alalite.org/files/lColoquio/docs/Ferraz.pdf. Acesso em: 07 fev. 2019.

HALBWACHS, M. A memória coletiva. Trad. de Beatriz Sidou. São Paulo: Centauro, 2006.

NOGUEIRA, Carlos Roberto F. O diabo no imaginário cristão. São Paulo, Editora Ática, 1986. WATT, lan. Mitos do individualismo moderno - Fausto, Dom Quixote.

Dom Juan, Robinson Crusoé. Rio de Janeiro, Jorge Zahar Editor, 1997.

MACHADO, Regina. O violino cigano e outros contos de mulheres sábias. São Paulo: Companhia das Letras, 2004.

MAGALHAES, JR. O diabo existe? Rio de Janeiro: Arte Nova, 1973. Tomo I.

MEIRELES, Cecilia. Problemas de Literatura Infantil. São Paulo: Global, 2016.

MESSADIÉ, Gerald: História Geral do Diabo: da Antiguidade à Época Contemporânea. Tradução de Alda Sophie Vinda. Portugal: EuropaAmérica, 2001.

MOURE, Gonzalo. Há razões para ignorar a literatura infantil, diz escritor espanhol. O Estado de São Paulo, São Paulo, 7 mar. 2013. Estadão Educação. Disponível em: https://educacao.estadao.com.br/noticias/geral,ha-razoes-para-ignorar-aliteratura-infantil-diz-escritor-espanhol,1005815.Acesso em: 03 jan. 2019. Entrevista concedida a Aryanne Carraro.

ZUMTHOR, Paul. A letra e a voz: a "literatura" medieval. Tradução de FERREIRA, Jerusa Pires; PINHEIRO, Amálio. São Paulo: Companhia das Letras, 1993.

Data da Submissão: 08/04/2019

Data da Aprovação: 13/06/2019 